\title{
Co-localization of elements required for phorbol ester stimulation and glucocorticoid repression of proliferin gene expression
}

\author{
John C. Mordacq and Daniel I.H. Linzer \\ Department of Biochemistry, Molecular Biology, and Cell Biology, Northwestern University, Evanston, Illinois 60208 USA
}

Proliferin (PLF) gene expression provides a model of growth-related transcriptional activation in mouse cells. Transcription from a cloned PLF promoter is inducible by phorbol esters, and this induction involves a region of 31 bp that includes an AP-1 site and a cluster of sites similar to the simian virus 40 (SV40) SphI element. The mutation of either the AP-1 or the SphI sites abolishes phorbol ester induction, and the transfer of this 31-bp sequence to a site upstream of a minimal promoter is sufficient to confer phorbol-ester responsiveness. In contrast to phorbol esters, glucocorticoids repress PLF transcription, which results in a reduced accumulation of PLF mRNA in serum-stimulated cells. Repression is dependent on the glucocorticoid receptor, which binds to the PLF promoter in a region that includes the AP-1 site, and the 31-bp phorbol ester 12-O-tetra decanoylphorbol-13-acetate (TPA)-inducible region is sufficient to mediate glucocorticoid repression. In addition, extracts from glucocorticoid-treated and untreated mouse cells are found to differ in the nature of the protein complexes that interact with the AP-1 site.

[Key Words: Proliferin; AP-1; Jun; glucocorticoid; glucocorticoid receptor]

Received January 30, 1989; revised version accepted April 7, 1989.

Proliferin (PLF), also known as mitogen-regulated protein, is a member of the prolactin/growth hormone family in the mouse (Linzer and Nathans 1984a; Parfett et al. 1985) that is synthesized specifically in vivo in placental trophoblasts (Linzer et al. 1985; Lee and Nathans 1987; Lee et al. 1988). At least two forms of PLF are synthesized from multiple gene copies (Wilder and Linzer 1986) as 224-amino-acid precursors and secreted as glycoproteins of 195 amino acids (Linzer and Nathans 1984a; Linzer et al. 1985; Lee and Nathans 1987). The function of PLF is unknown, although recent evidence indicates that one form of this protein can inhibit cellular differentiation in culture (Wilder and Linzer 1989).

Synthesis of PLF mRNA and protein is detected in several cultured mouse cell lines, where synthesis occurs in a growth-related manner; PLF mRNA is not detected in quiescent mouse cell cultures, but stimulation of these cells with serum, platelet-derived growth factor, or phorbol esters results in the accumulation of this mRNA in the $G_{1}$ phase (Nilsen-Hamilton et al. 1980; Linzer and Nathans 1983, 1984b; Fienup et al. 1986). This increase in PLF mRNA concentration results from both transcriptional (Linzer and Mordacq 1987) and post-transcriptional (Linzer and Wilder 1987) events and is dependent on new protein synthesis within the first 2 $\mathrm{hr}$ after serum stimulation (Linzer and Wilder 1987).

As part of the initial response to mitogenic stimula- tion, cultured mouse cells activate the expression of several genes that encode known or putative transcription factors (Greenberg and Ziff 1984; Milbrandt 1987 1988; Chavrier et al. 1988; Christy et al. 1988; Cohen and Curran 1988; Hazel et al. 1988; Joseph et al. 1988; Lamph et al. 1988; Lemaire et al. 1988; Ryder and Nathans 1988; Ryder et al. 1988; Ryseck et al. 1988; Sukhatme et al. 1988). Among these are at least three related transcription factors that recognize a common element that is responsible for mediating induction by phorbol esters (Angel et al. 1987; Lee et al. 1987): c-Jun/ AP-1 (Bohmann et al. 1987; Angel et al. 1988), and Jun-B and Jun-D (Ryder et al. 1988; Nakabeppu et al. 1988).

Increases in activity of the AP-1 transcription factor family have been attributed not only to increases in the levels of these proteins after serum stimulation of resting mouse fibroblasts, but also to post-translational events. Most notable is the formation of heterodimers between AP-1 or related factors and the mitogen-inducible Fos protein (Chiu et al. 1988; Rauscher et al. 1988; Sassone-Corsi et al. 1988), which results in greater DNA-binding activity to AP-1 sites (Nakabeppu et al. 1988; Halazonetis et al. 1988). The findings that PLF synthesis can be stimulated by phorbol esters (Fienup et al. 1986), and that PLF expression is dependent on new protein synthesis early in the $G_{0}$ to $G_{1}$ transition (Linzer and Wilder 1987) indicate that the PLF genes are targets 
of the AP-1 factor family. Therefore, PLF expression may provide a useful system for the investigation of the actions of these mitogen-induced transcription factors, and for the elucidation of the steps in the pathway that lead from mitogenic stimulation to DNA synthesis.

PLF expression is regulated not only by an increase in mRNA synthesis during $G_{1}$, but also by a decrease in mRNA levels as cells exit $G_{1}$ and as cell cultures achieve high cell density (Linzer and Nathans 1983). The basis of this downregulation is not known, although the 3 '-untranslated region of PLF mRNA does include the sequence AUUUA (Linzer and Nathans 1984a), which has been shown to destabilize other mRNAs (Shaw and Kamen 1986). Although turnover of existing mRNA molecules may account for part of the decrease in PLF mRNA concentration, it is likely that downregulation of PLF transcription also occurs. This downregulation may be the result of the loss or inactivation of positive factors required for PLF transcription, or of the action of specific repressor molecules. Because transcription from the closely related prolactin gene can be repressed by glucocorticoids (Camper et al. 1985; Sakai et al. 1988), we investigated the possibility that steroid hormones may also regulate PLF transcription.

In this report, we analyze the effects of the phorbol ester 12-O-tetradecanoyl-phorbol-13-acetate (TPA) and the synthetic glucocorticoid dexamethasone on the activity of a PLF gene promoter (Linzer and Mordacq 1987). Our findings indicate that TPA induction of the PLF promoter involves a region that includes both an AP-1 site and additional elements similar in sequence to the simian virus 40 (SV40) SphI sites (Herr and Clarke 1986; Zenke et al. 1986). Furthermore, we describe the negative regulation of PLF transcription by glucocorticoids and demonstrate that this effect is mediated through this TPA-inducible region.

\section{Results \\ Phorbol ester induction of a PLF promoter}

We demonstrated previously that a 670-bp fragment of a PLF promoter is sufficient to mediate serum induction of a linked bacterial chloramphenicol acetyltransferase (CAT) gene in transiently transfected mouse L cells (Linzer and Mordacq 1987). To determine if this promoter fragment is also sufficient to confer TPA induction, $\mathrm{L}$ cells transfected with this PLF-CAT construct were cultured in the presence or absence of TPA and then assayed for CAT activity (Fig. 1A). A fivefold increase in CAT activity was obtained with the 670-bp promoter region, and a corresponding increase in the appropriate transcript was detected by $\mathrm{S} 1$ nuclease analysis (Fig. 1C). This fivefold induction was also seen with a $5^{\prime}$ deletion from position -232 (relative to the transcription start site) and with an internal deletion that removed sequences between -189 and -37 (Fig. 1A).

Within the region between -189 and -232 is an 8 -bp sequence (TTAGTCAG at residues -231 to -224 ) that is identical to the SV40 AP-1 site (Fig. 1B); site-directed mutation of this sequence (at -227 through -224 ; Fig. 1B) abolished the response of the 670-bp promoter to TPA (Fig. 1A). It was expected, therefore, that deletion of sequences downstream of this AP-1 site would not affect TPA induction. However, internal deletions of sequences from -37 to -220 and from -37 to -214 , and a linker-scanner mutation from -220 to -211 (Fig. 1B), also eliminated induction (Fig. 1A), which indicated that the AP-1 site was not the only element required for TPA induction.

This region immediately downstream of the AP-1 site contains sequences similar to the SphI sites in the SV40 promoter that have been reported to bind transcription factor TEF-1 (Davidson et al. 1988). These SphI-like sequences are present in the PLF promoter as a cluster of three imperfect repeats (Fig. 1B). The loss of TPA-induced activity by deletion of sequences from -37 to -214 indicated that the AP-1 element plus only the first SphI repeat was insufficient for a TPA response; a similar loss in inducible activity with the $-220 /-211$ linker-scanner mutant promoter indicated that the third SphI repeat in concert with the AP-1 site was also insufficient for TPA responsiveness. Thus, it seems likely that this cluster of imperfectly repeated sites is necessary for promoter activity.

To verify that these putative AP-1 and SphI sites are recognized by specific proteins, an end-labeled promoter fragment was incubated with a whole-cell extract from serum-stimulated BALB/c $3 \mathrm{~T} 3$ cells and then treated with exonuclease III. Partial digestion products were detected at the $3^{\prime}$ boundary of the AP-1 site $(-225)$ and the $3^{\prime}$ boundary of the clustered SphI site repeats $(-204$ and -207 ), which indicated that proteins had bound at those sites and thereby had prevented further digestion by the enzyme (Fig. 2.). Binding to the AP-1 site is independent of binding to the SphI repeats, as exonuclease mapping of a promoter fragment that lacks the $3^{\prime}$ half of SphI site I and all of sites II and III still reveals a stop at -225 (data not shown).

Support for the finding that elements in addition to the AP-1 site are important for TPA induction was also found by the transfer of sequences up stream of a herpes simplex virus-1 thymidine kinase minimal promoter linked to CAT. This basic construct (TK-CAT) contained promoter sequences from -37 to +57 and included the TATA box but no additional promoter elements (McKnight and Kingsbury 1982). TK-CAT is expressed at very low levels in transfected $L$ cells and is induced only slightly by TPA (Fig. 3). Inclusion of the PLF AP-1 element to generate A-TK-CAT, which at that point contained PLF sequences from -234 to -219 , resulted in a slight increase in the basal level of CAT activity and in a two- to threefold induction by TPA (Fig. 3). (Note that -234 to -219 was selected to include the AP-1 site and a few flanking nucleotides on either side and, as such, actually included a portion of SphI site I.) However, an even higher basal activity and a greater response to TPA (five- to sixfold) was obtained by the placement of a 31-nucleotide sequence $(-234$ through -204) that contained the AP-1 site and SphI re- 
A.

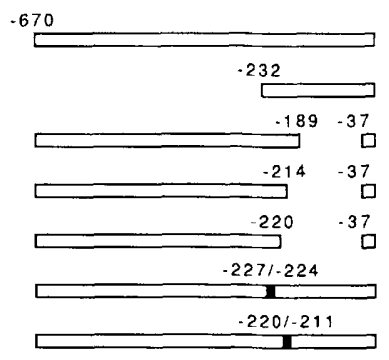

RELATIVE CAT ACTIVITY

(+ TPA / - TPA)

5.0

4.8

1.0

1.1

1.3

1.1

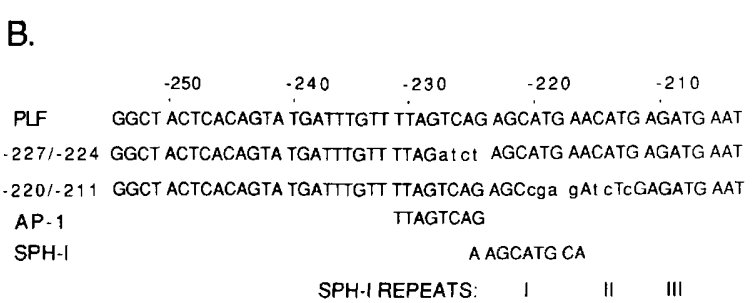

B.

PEPEATS: I "

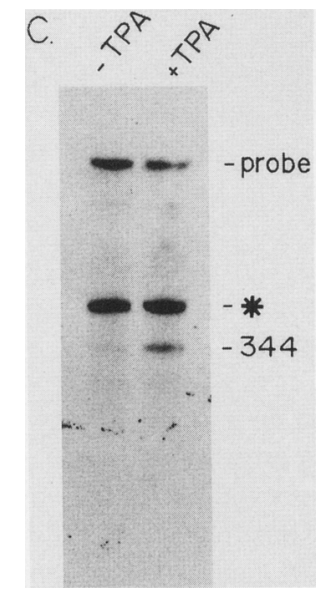

Figure 1. TPA induction of the PLF promoter. $|A|$ The regions of the PLF promoter linked to CAT coding sequences are shown alongside the relative CAT activities recovered from mouse $\mathrm{L}$ cells treated with or without $60 \mathrm{ng} / \mathrm{ml} \mathrm{TPA}$ after transfection with these constructs. Each construct was assayed at least twice. Basal activity (-TPA) was $\sim 0.5-1 \%$ conversion of chloramphenicol to acetylated forms for the uninducible mutants and $2.5-5 \%$ for the -670 construct. $(B)$ The sequences of the wild-type PLF promoter from -254 to -204 , the two linker-scanner mutants, and the SV40 AP-1 and SphI sites are indicated, along with the locations of the imperfect SphI repeats. $(C)$ RNA from TPA-treated or untreated L cells transfected with PLF-CAT was subjected to S1 nuclease analysis. The 344-nucleotide protected fragment represents transcription from the correct start site; the fragment marked by the asterisk $\left({ }^{*}\right)$ corresponds to an upstream start site that serves as an internal control (Linzer and Mordacq 1987).

peats upstream of the TATA element to generate AS-TK-CAT (Fig. 3); this degree of induction is similar to that found for the intact PLF promoter.

\section{Negative regulation of PLF expression by glucocorticoids}

A possible effect of glucocorticoids on PLF expression was first assessed by the treatment of serum-stimulated $\mathrm{C} 3 \mathrm{H} 10 \mathrm{~T}^{1 / 2} 2$ cells with dexamethasone. RNA was purified from these cultures at late $G_{1}, 10 \mathrm{hr}$ after the addition of serum and dexamethasone, and was hybridized to PLF cDNA. Dexamethasone treatment resulted in an approximately fourfold decrease in the level of PLF mRNA relative to that present in serum-stimulated cells that were not treated with this steroid hormone (Fig. 4A). The filter was rehybridized to a probe for mouse $\beta$-tubulin, which revealed that dexamethasone addition did not lower the levels of this mRNA in serum-stimulated cultures (Fig. 4B). A similar reduction in PLF mRNA levels in response to dexamethasone was also obtained in BALB/c 3T3 cells (data not shown).

If down-regulation of PLF mRNA levels is transcriptional, then dexamethasone should repress growth factor-induced PLF-CAT expression. As predicted, CAT activity was reduced four- to sixfold in L-cell cultures transfected with PLF-CAT and treated with dexamethasone; this negative effect was observed in cultures stimulated either with serum (Fig. 5A) or with TPA (data not shown). In comparison, dexamethasone-induced CAT expression from the mouse mammary tumor virus (MMTV) promoter and had no effect on expression from the Rous sarcoma virus (RSV) promoter (Fig. 5A). S1 nuclease analysis verified that the decrease in CAT activity in dexamethasone-treated L-cell cultures transfected with PLF-CAT was the result of decreased RNA transcript levels. (Fig. 5B).

\section{Interaction of the glucocorticoid receptor with the PLF promoter}

Both positive and negative effects of glucocorticoids on transcription invariably have been found to be dependent on the glucocorticoid receptor. To determine if repression of PLF transcription is also receptor dependent, Chinese hamster ovary $(\mathrm{CHO})$ cells that lacked endogenous glucocorticoid receptor were cotransfected with PLF-CAT and RSV-GR, an expression plasmid for the rat glucocorticoid receptor (Miesfeld et al. 1986), or PLF-CAT and RSV-NEO (Gorman et al. 1983) as a negative control. Parallel transfections of MMTV-CAT into $\mathrm{CHO}$ cells demonstrated that cotransfection of this glucocorticoid receptor construct was sufficient for transcriptional activation in response to dexamethasone (Fig. 6). Although the PLF promoter is much weaker in CHO cells than in mouse $\mathrm{L}$ cells, dexamethasone treatment had no effect on expression from this promoter in the absence of the glucocorticoid receptor, but did result 


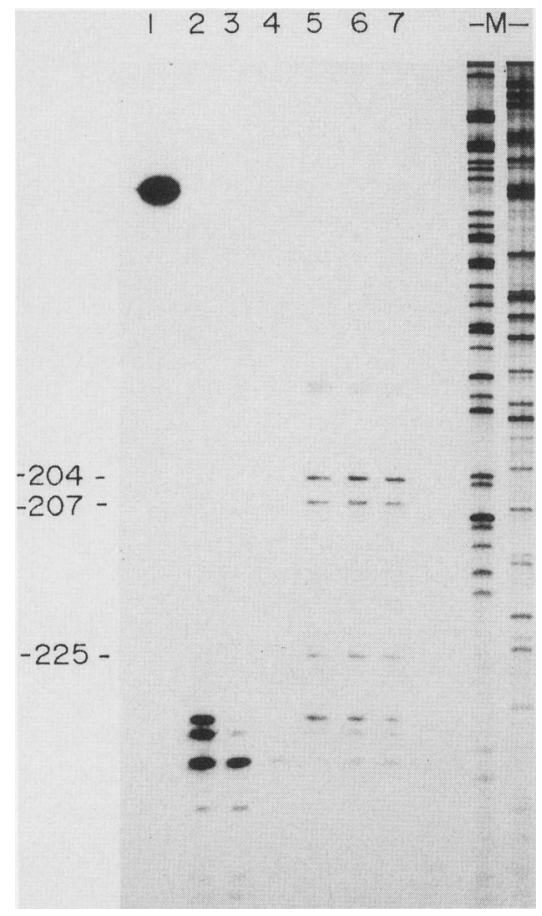

Figure 2. Exonuclease III footprinting of the PLF promoter. A PLF promoter fragment of 116 bp labeled at -256 was incubated with BALB/c $3 \mathrm{~T} 3$ whole-cell extract and digested with exonuclease III. The major specific stops are at -204 or -207 (the $3^{\prime}$ boundary of the SphI repeat cluster) and -225 (the $3^{\prime}$ boundary of the AP-1 site). (Lane 1) Undigested probe; (lanes 2-4) heat-denatured whole-cell extract with increasing amounts of exonuclease III; (lanes 5-7) whole-cell extract with increasing amounts of exonuclease III; (lanes $M$ ) sequencing reaction markers.

in lower levels of CAT activity in cultures that were synthesizing the glucocorticoid receptor (Fig. 6). Thus, downregulation of the PLF promoter by dexamethasone is dependent on glucocorticoid receptor.

The glucocorticoid receptor induces transcription by binding to a specific DNA sequence (Chandler et al. 1983), and receptor binding to other sequences may be required for repression (Akerblom et al. 1988; Sakai et al. 1988). Binding of glucocorticoid receptor to the PLF promoter was therefore examined by DNase I footprinting by use of the purified DNA-binding domain of the glucocorticoid receptor (Freedman et al. 1988). This receptor fragment protected a 30-bp sequence between -254 and -225 on the sense strand, and between -252 and -230 on the antisense strand; this region included the AP-1 site (at -231 to -224 ) and sequences upstream of this site (Fig. 7). No other sites of equivalent affinity for the glucocorticoid receptor were detected from -1 to -600 .

The ability of this protein to bind to PLF gene sequences that overlap the region responsible for TPA induction indicates that glucocorticoid repression of PLF transcription may be accomplished by competition among factors for binding sites, or by inhibitory interactions among factors associated with this upstream re- gion. However, the TPA-inducible promoter deleted to -232 remains repressible by dexamethasone, even though footprint analysis with the glucocorticoid receptor fragment did not reveal significant protection (data not shown). It is possible that such an in vitro assay with a receptor fragment does not reflect accurately the in vivo affinity of the full-length receptor protein for the PLF AP-1 region in the absence of the upstream portion of the footprint.

\section{Glucocorticoid repression through the TPA-inducible region}

The interaction of receptor protein with a portion of the region required for the response to TPA, and the ability of glucocorticoids to down-regulate TPA-induced transcription from the $5^{\prime}(-232)$ deletion mutant, indicates that the negative glucocorticoid regulatory elements in the PLF gene may colocalize with the TPA-response region. To examine this possibility, we analyzed the effect of dexamethasone on AS-TK-CAT expression in transfected L-cell cultures; repression was seen in terms of CAT activity (Fig. 8A) and RNA levels (Fig. 8B). For the RNA analysis, the RSV-CAT construct was included in the transfections as an internal control; transcripts from this promoter appeared to be reduced in amount by TPA treatment and restored by addition of dexamethasone (Fig. 8B), presumably because the RSV and the AS-TK

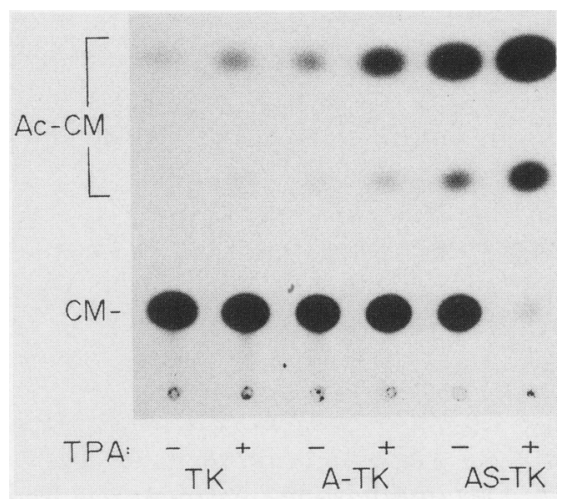

Figure 3. Minimal region of the PLF promoter required for TPA induction. Mouse L cells were transfected with: a minimal promoter linked to CAT (TK-CAT); the TK-CAT construct augmented by PLF promoter sequences from -234 to -219 , which included the AP-1 site $(\mathrm{A}-\mathrm{TK}-\mathrm{CAT})$; or promoter sequences from -234 to -204 , which included the AP-1 site and SphI site cluster (AS-TK-CAT). Transfected cultures were maintained with or without TPA, and extracts were assayed for conversion of chloramphenicol (CM) to acetylated forms (AcCM). CAT activities were $2.2 \%$ and $4.4 \%$ conversion for TKCAT ( - and + TPA) and $6.2 \%$ and $17.4 \%$ for A-TK-CAT $1-$ and + TPA); these values were confirmed in two additional experiments. In this experiment, percent conversion for AS-TK-CAT transfected cell extracts could not be measured accurately, because available substrate was exhausted; the fiveto sixfold TPA induction of expression from this construct, as reported in the text, was determined from four independent experiments. 
Figure 4. Glucocorticoid inhibition of PLF mRNA accumulation. Quiescent $\mathrm{C} 3 \mathrm{H} 10 \mathrm{~T}^{1} / 2$ cells were stimulated with serum in the presence or absence of $0.1 \mu \mathrm{M}$ dexamethasone. Total cellular RNA was isolated and hybridized to PLF CDNA $(A)$ and then to mouse $\beta$ tubulin cDNA $(B)$.

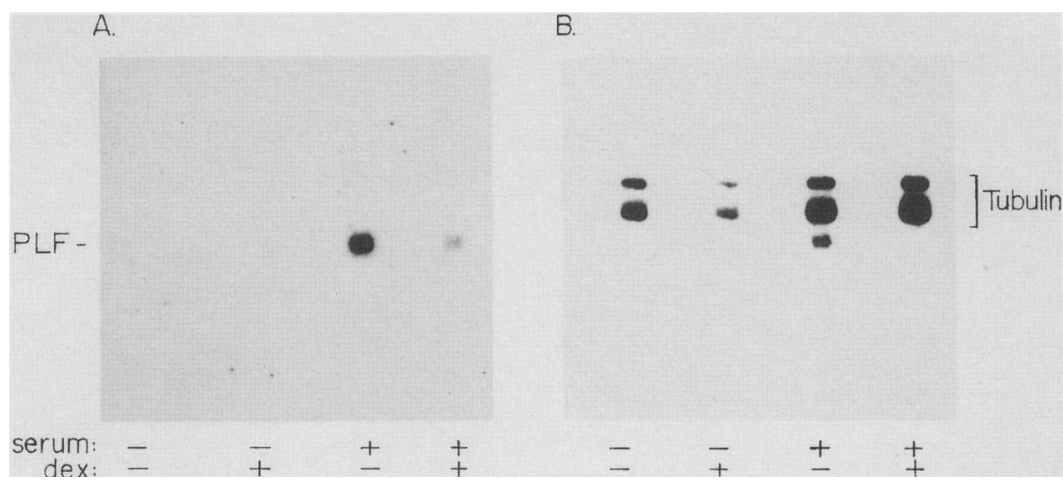

\section{Discussion}

Promoter elements involved in the phorbol-ester induction of PLF transcription

The response of a quiescent cell to a mitogenic stimulus involves the activation of a program of gene expression during the $G_{1}$ phase that leads to renewed DNA synthesis. As part of this program, transcription of the AP-1 and associated fos gene families occurs rapidly (Greenberg and Ziff 1984; Cohen and Curran 1988; Lamph et al. 1988; Ryder and Nathans 1988; Ryder et al. 1988; Ryseck et al. 1988), whereas other genes, such as PLF (Linzer and Nathans 1983), are expressed later in $G_{1}$. Our results demonstrate that these events are connected, as increased transcription from a PLF promoter in response to the phorbol ester TPA is dependent on a functional AP-1 site. However, this AP-1 site is not the only element involved in promoter response to TPA; a region that includes three imperfect repeats similar in sequence to the SV40 SphI sites and that lies immediately downstream of the AP-1 element is also necessary for TPA induction. The organization of these PLF promoter elements is thus strikingly similar to that of the SV40 enhancer, which contains closely spaced AP-1 and SphI sites. Although the AP-1/SphI region of the PLF gene is able to confer TPA inducibility on a heterologous pro-

Figure 5. Glucocorticoid down-regulation of the PLF promoter. $(A)$ Mouse L cells were transfected with PLF-CAT, RSV-CAT, or MMTV-CAT and maintained in $10 \%$ serum with or without dexamethasone. Cell extracts were prepared and assayed for CAT enzymic activity. In this experiment, conversion values were: PLF, $6.7 \%(-$ dexamethasone) and $1.5 \%(+)$; RSV, $24.5 \%(-)$ and $28.8 \%(+)$; MMTV, $0.3 \%(-)$ and $23.2 \%(+)$. A similar degree of down-regulation for PLF-CAT was found in five additional transfections. $(B)$ RNA isolated from $L$ cells transfected with PLFCAT was hybridized to a DNA probe and treated with S1 nuclease. The 344-nucleotide protected fragment corresponds to accurately initiated transcripts from the PLF promoter; an asterisk $\left({ }^{*}\right)$ marks the fragment from an upstream start that was used as an internal control. Markers were end-labeled DNA fragments from pBR322 digested with HinfI.

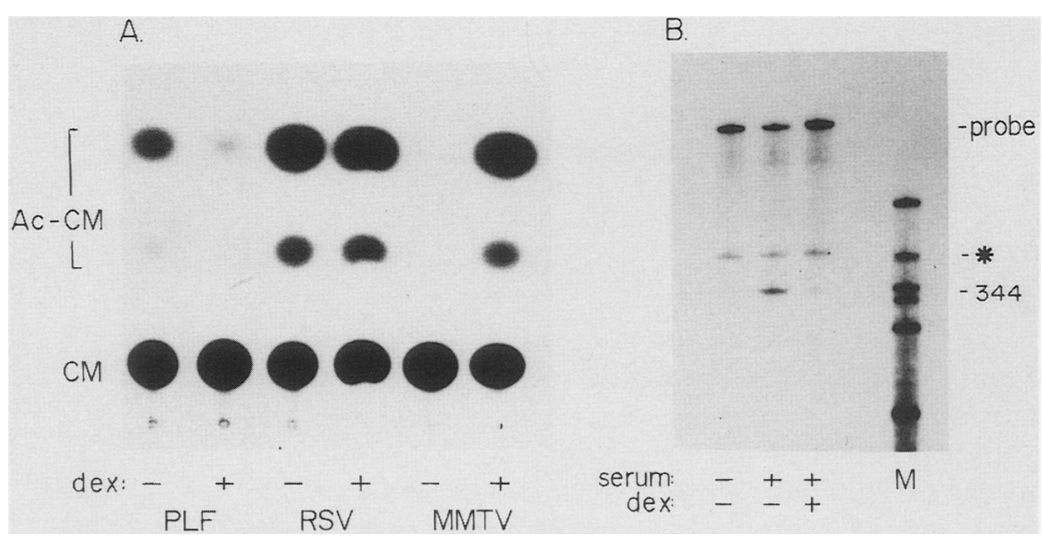




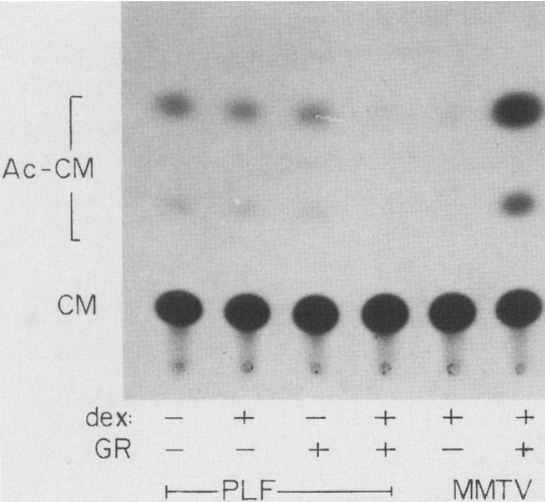

Figure 6. Dependence of glucocorticoid repression on glucocorticoid receptor. PLF-CAT or MMTV-CAT DNA was transfected into CHO cells along with the RSV-GR or RSV-NEO construct. Cultures were treated with or without dexamethasone, and cell extracts were assayed for CAT activity. CAT activities were (left to right): $1.7 \%$ and $1.4 \%$ (1.2-fold decrease); $1.4 \%$ and $0.3 \%$ (4.7-fold decrease); and $0.3 \%$ and $12.3 \%(40$-fold increase).

moter, these elements are unlikely to account completely for the growth-related transcription of PLF, as serum responsiveness appears to involve additional elements located upstream of the AP-1 site (J. Mordacq and D. Linzer, unpubl.). Furthermore, the high basal activity conferred by the AP- $1 / \mathrm{SphI}$ region on the minimal TK

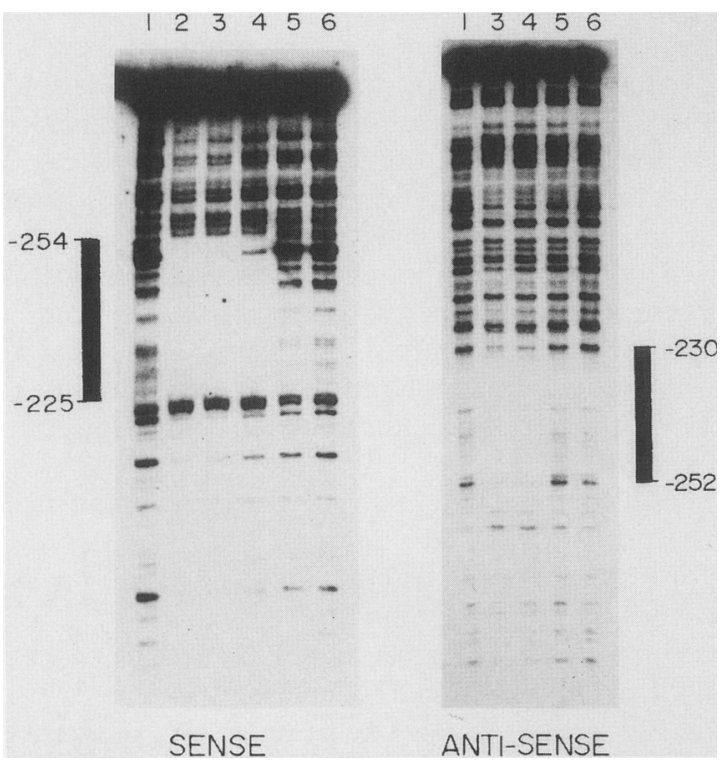

Figure 7. Binding of glucocorticoid receptor to the PLF promoter. PLF promoter fragments of 147 bp labeled at -153 (which revealed protection on the sense strand) or of $168 \mathrm{bp}$ labeled at -316 (which showed protection on the antisense strand) were incubated without the glucocorticoid receptor DNA-binding fragment (lane 1), or with this purified protein at $1.5 \mu \mathrm{g}$ (lane 2), $1 \mu \mathrm{g}$ (lane 3); $500 \mathrm{ng}$ (lane 4), $250 \mathrm{ng}$ (lane 5), or $125 \mathrm{ng}$ (lane 6). Samples were digested partially with DNase I and then electrophoresed.

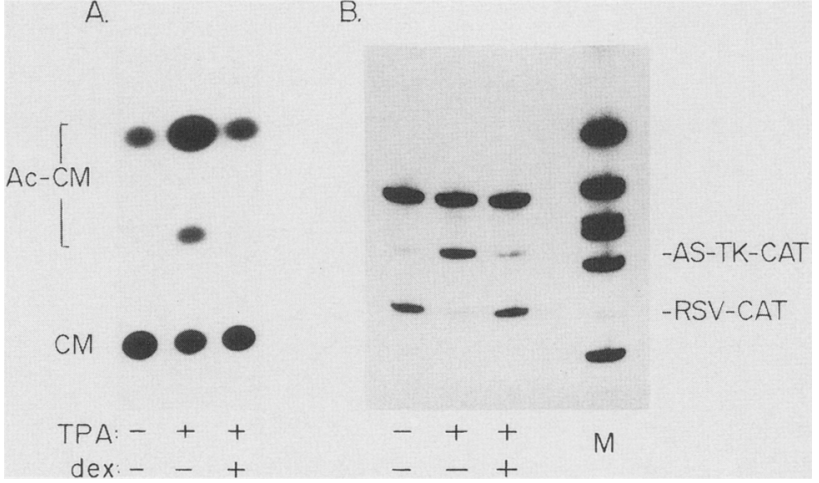

Figure 8. Glucocorticoid repression through the AP-1/SphI region of the PLF promoter. (A) The AS-TK-CAT construct was transfected into mouse cells, which were maintained with or without TPA and dexamethasone. Cell extracts were assayed for CAT activity, which were $16.5 \%$ - TPA, - dexamethasone), $72.4 \%$ (+ TPA, - dexamethasone), and 21.1\% (+ TPA, + dexamethasone); dexamethasone treatment of uninduced cultures resulted in an approximately twofold decrease in CAT activity. Similar results were seen in four independent transfections. $(B)$ RNA, purified from $\mathrm{L}$ cells cotransfected with AS-TK-CAT and RSV-CAT and treated with or without TPA and dexamethasone, was hybridized to a DNA probe and incubated with S1 nuclease. Fragments protected by AS-TK-CAT and RSV-CAT transcripts are indicated; the upper band represents undigested probe.

promoter suggests that the activity of this region within the PLF gene (which has a low basal level of expression) may be limited by other regulatory elements.

Factors involved in the response of the PLF promoter to phorbol esters

At least two transcription factors are implicated in the TPA induction of PLF gene expression, those that interact with the AP-1 and SphI-like sites. A factor that binds to the SV40 SphI sites has been purified from HeLa cells, and designated TEF-1 (Davidson et al. 1988). This factor appears to require tandem repeats of a binding site, and binding occurs cooperatively (Davidson et al. 1988). The repeats of an SphI-like sequence present in the TPA-inducible region of the PLF gene therefore may be targets for the mouse homolog of the human TEF-1 protein. By use of exonuclease III, protein binding is detected only at the $3^{\prime}$ boundary of the SphI cluster. If the two upstream sites are used also, then the inability to detect additional nuclease stops in these repeats may be explained by cooperative binding, a characteristic of TEF-1. Thus, any template molecule with bound factor likely will have all three SphI sites occupied, and only a stop at the end of the cluster will be seen.

In contrast to the possible cooperativity in binding within the SphI cluster, binding to the SphI and AP-1 sites appears to be independent. The detection of an exonuclease stop at the AP-1 site indicates that some molecules in the population have factors bound to this ele- 


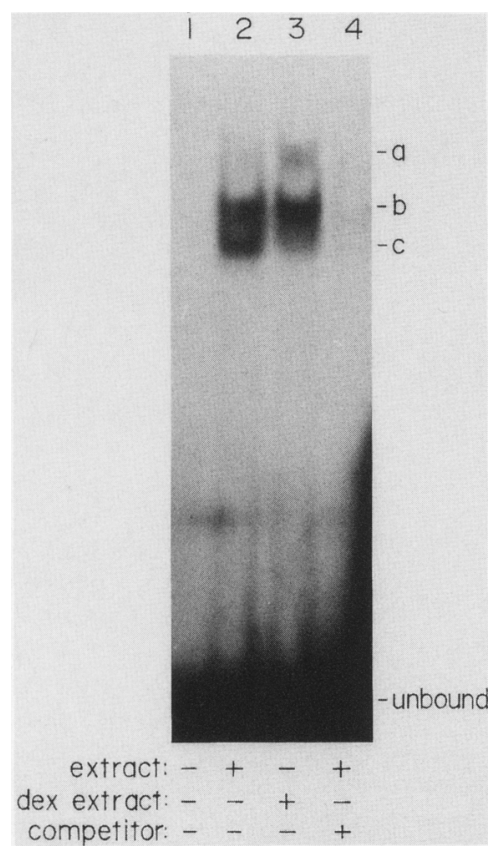

Figure 9. Effect of glucocorticoids on protein-DNA complexes at the AP-1 site. The double-stranded AP-1 oligonucleotide was incubated with whole-cell extracts from BALB/c 3T3 cells treated with or without dexamethasone, and bound complexes were fractionated from unbound DNA by gel electrophoresis. Competitor (100-fold excess of unlabeled double-stranded AP-1 oligonucleotide/ was added to one reaction to demonstrate the specificity of the bound complex; a similar excess of an unlabeled double stranded oligonucleotide that lacked the AP-1 site did not compete any of the three gel-shifted species (data not shown). Gel-shifted species are indicated as $a, b$, and $c$.

ment and not to the downstream SphI repeats, and binding to the AP-1 element in the absence of the SphI sites is seen by both exonuclease III and gel-retardation assays. It is not yet clear which of the known factors in the AP-1 family is responsible for binding to this site, but on the basis of the mitogen-induced expression (Lamph et al. 1988; Ryder and Nathans 1988; Ryseck et al. 1988) and indistinguishable binding activities of AP-1/c-Jun, Jun-B, and Jun-D (Nakabeppu et al. 1988), it seems likely that all three of these proteins are capable of interacting with the PLF promoter.

\section{Negative regulation of PLF expression}

The ability of glucocorticoids to repress PLF transcription in cultured mouse cells may not be directly relevant to the transition from cellular quiescence to growth, because a role for the glucocorticoid receptor in cell-cycle regulation has not been reported. However, because repression of PLF transcription occurs through sequences that mediate phorbol-ester induction, this system may provide insights into the regulation of growth-associated transcription-factor activity. In particular, the negative effect of glucocorticoids on the activity of the $31-\mathrm{bp}$
TPA-responsive region suggests that repression may also be found for other genes that use AP-1 or SphI elements. /Consistent with this prediction is the recent observation of glucocorticoid repression through the SV40 enhancer; D. Israel, pers. comm.).

Several genes are repressed transcriptionally by glucocorticoids (Camper et al. 1985; Israel and Cohen 1985; Charron and Drouin 1986; Frisch and Ruley 1987; Weiner et al. 1987; Guertin et al. 1988), and two distinct models have been offered to account for this effect: glucocorticoid receptor inhibition of transcription-factor activity by protein-protein interactions (Adler et al. 1988) or competition for DNA-binding sites between receptor and positive factors (Akerblom et al. 1988; Oro et al. 1988; Sakai et al. 1988). If the latter model is correct, it should be noted that no consensus sequence for a negative glucocorticoid response element is apparent from the collection of genes studied thus far. Furthermore, the affinity of receptor for these negative elements appears to be reduced compared to its affinity for the positive glucocorticoid regulatory elements (Sakai et al. 1988).

Our results with the PLF gene do not yet rule out either model of glucocorticoid action. The receptor binds in vitro to an upstream region of the PLF gene that overlaps the TPA-responsive region, which indicates that competition for DNA binding at this locus may occur, but glucocorticoid inhibition of transcription is still observed when most of this receptor-binding site is removed. Furthermore, distinct protein complexes can assemble on the AP-1 oligonucleotide from dexamethasone-treated and untreated cells; this may be the result of the addition of receptor to the complex (consistent with the larger size of the glucocorticoid-dependent complex|, to displacement of one or more of the proteins in the complex by receptor, to glucocorticoid-dependent modification of proteins in the complex, or to glucocorticoid-induced or repressed expression of other genes that encode transcription factors that interact with this PLF gene region. It will be essential to determine the composition of the protein complexes associated with the TPA-inducible region of the PLF gene to understand the basis of glucocorticoid repression of transcription in this system.

Finally, the negative effect of glucocorticoids on PLF transcription may be an important feature of the regulation of PLF expression in vivo. Glucocorticoid levels increase during pregnancy in rodents (Dupouy et al. 1975), which may lead to decreased PLF transcription in placental trophoblasts and the observed decrease in placental PLF mRNA levels late in pregnancy (Linzer et al. 1985). Indeed, preliminary results indicate that secretion of PLF protein is reduced in primary placental cultures treated with dexamethasone (J. Mordacq and D. Linzer, unpubl.). Although the function of PLF during pregnancy is unknown, it is possible that placental expression of PLF, and perhaps of the other hormones in the prolactin/growth hormone family (Ogren and Talamantes 1988), and adrenal expression of glucocorticoids are linked in a regulatory cycle. 


\section{Materials and methods}

\section{Plasmid constructions}

The construct that contained 670 bp upstream of the transcription start site from a PLF promoter linked to CAT has been described (Linzer and Mordacq 1987); this construct was designated originally as PLF-CATADD, but is now referred to simply as PLF-CAT. Deletions $\left(5^{\prime}\right.$ and $\left.3^{\prime}\right)$ were generated by Bal31 digestion of the promoter fragment, with deletion end points determined by DNA sequencing; linker-scanner mutations were made by the combination of appropriate $5^{\prime}$ and $3^{\prime}$ deletions. Additional promoter mutants were produced by oligonucleotide-directed mutagenesis (Zoller and Smith 1984). Doublestranded oligonucleotides were synthesized to correspond to the AP-1 site (5'-AATTCGTTTTAGTCAGAGCAT- 3 ' and $5^{\prime}$ CGATGCTCTGACTAAAACG-3') or AP-1 site along with the SphI repeats $\left(5^{\prime}\right.$-GATCCGTTTTAGTCAGAGCATGAACATGAGATGAATG-3' and 5'-AATTCATTCATCTCATGTTCATGCTCTGACTAAAACG-3') were cloned into the polylinker of a plasmid vector (pSP72, Promega), then excised and inserted into TK-CAT. The TK-CAT vector was constructed by the replacement of the promoter region in pOTCO-CAT (DeFranco and Yamamoto 1986) with the -37 to +57 fragment of the herpes virus 1 thymidine kinase promoter (McKnight and Kingsbury 1982). Other constructs used in these studies were RSV-CAT (Gorman et al. 1982b), MMTV-CAT (Majors and Varmus 1983), RSV-GR (Miesfeld et al. 1986), RSV-NEO (Gorman et al. 1983), and a mouse $\beta$-tubulin cDNA close (Sullivan and Cleveland 1986). All plasmids were propagated in Escherichia coli DH5 cells and purified by $\mathrm{CsCl}-$ ethidium bromide gradient centrifugation.

\section{Isolation and analysis of RNA}

Total cellular RNA was purified from guanidinium thiocyanate cell lysates (Chirgwin et al. 1979) by centrifugation through $\mathrm{CsCl}$ (Gilisin et al. 1974). For Northern analysis, RNA was fractionated by formaldehyde-agarose gel electrophoresis, transferred to nitrocellulose, and hybridized to nick-translated PLF cDNA (Linzer and Nathans 1984a) as described by Jackson et al. (1986). For S1 analysis, RNA was hybridized to a DNA probe for $12-16 \mathrm{hr}$ at $44^{\circ} \mathrm{C}$ in $10 \mu \mathrm{l}$ of $80 \%$ formamide, $40 \mathrm{mM}$ PIPES (pH 6.4), and $1 \mathrm{mM}$ EDTA. The DNA probe was a fragment from PLF-CAT or TK-CAT labeled at the EcoRI site in the CAT-coding sequences (see Linzer and Mordacq 1987); the DNA fragments were treated with calf intestinal alkaline phosphatase and labeled with $\left[\gamma^{-32}\right]$ ATP and T4 polynucleotide kinase. Hybridized samples were digested with 200 units of S1 nuclease and electrophoresed on $6 \%$ polyacrylamide- $50 \%$ urea gels.

\section{Cell culture and DNA transfections}

Mouse L cells were maintained in Dulbecco's modified Eagle's medium (DMEM) supplemented with $10 \%$ calf serum. Approximately $2 \times 10^{6}$ cells were plated in $10-\mathrm{cm}$ dishes $24 \mathrm{hr}$ before DNA transfection (15 $\mu \mathrm{g} /$ dish) with DEAE-dextran (Lopata et al. 1984). After $4 \mathrm{hr}$, the medium was removed and the cells were exposed to a DMSO shock; cultures were then fed with fresh medium. Transfected cultures were maintained in DMEM containing $0.5 \%$ calf serum, stimulated with $15 \%$ serum or 60 $\mathrm{ng} / \mathrm{ml}$ TPA, or treated with $0.1 \mu \mathrm{M}$ dexamethasone. Cultures were fed with fresh medium the next day, and harvested $48 \mathrm{hr}$ post-transfection for RNA or protein analysis. $\mathrm{CHO}$ cells were grown in alpha medium with $10 \%$ fetal calf serum and were transfected as described previously, except that each $10-\mathrm{cm}$ dish received $8 \mu \mathrm{g}$ of the test plasmid and either $8 \mu \mathrm{g}$ of RSVGR or RSV-NEO. Mouse C3H $10 \mathrm{~T}^{1 / 2} / 2$ and BALB/c $3 \mathrm{~T} 3$ cells were grown in DMEM with $10 \%$ calf serum. Cell cultures were growth-arrested by the feeding of confluent monolayers with DMEM with $0.5 \%$ calf serum for 2 days and stimulated by addition of DMEM with $20 \%$ calf senum.

\section{Cell extracts, CAT assays, and gel shifts}

Protein extracts from transfected cell cultures were prepared by freeze-thaw lysis of harvested cells and assayed for CAT enzymatic activity as described (Gorman et al. 1982a). Equal amounts of protein extract, determined by a dye-binding assay (Bradford 1976), were incubated with $\left[{ }^{14} \mathrm{C}\right]$ chloramphenicol (New England Nuclear). CAT activity was detected by thinlayer chromatography of the reaction products and measured by liquid scintillation counting of the separated forms of chloramphenicol.

Whole-cell extracts were made from BALB/c 3 T3 cell cultures stimulated with serum or serum plus $0.1 \mu \mathrm{M}$ dexamethasone for $12 \mathrm{hr}$ (Zimarino and Wu 1987). Double-stranded AP-1 oligonucleotide (see above) was labeled with $\left[\gamma^{-32}\right.$ P]ATP and T4 polynucleotide kinase and incubated with the whole-cell extract in $25 \mu$ l of $25 \mathrm{~mm}$ HEPES (pH 7.5), $5 \mathrm{~mm} \mathrm{MgCl}_{2}, 20 \mathrm{~mm}$ $\mathrm{NaCl}, 2 \mathrm{mM}$ dithiothreitol (DTT), 100-200 pg of oligonucleotide, $10 \mu \mathrm{g}$ of extract, and $5 \mu \mathrm{g}$ poly[d(I-C)]. The reaction proceeded for $20 \mathrm{~min}$ at $25^{\circ} \mathrm{C}$, and protein-DNA complexes were visualized by $6 \%$ polyacrylamide gel electrophoresis in $22 \mathrm{~mm}$ Tris base, $0.6 \mathrm{~mm}$ EDTA, $22 \mathrm{~mm}$ boric acid (Piette et al. 1988), and autoradiography.

\section{DNase I and exonuclease III footprinting}

DNA fragments were labeled by the filling-in of restriction enzyme-generated ends with the Klenow fragment of DNA polymerase I and $\left[\alpha^{-32} \mathrm{P}\right] \mathrm{dATP}$. Fragments $(5-10$ fmoles per footprint reaction) were incubated in $20 \mu \mathrm{l}$ of $10 \mathrm{mM}$ Tris $-\mathrm{HCl}(\mathrm{pH} 7.5)$, $60 \mathrm{~mm} \mathrm{KCl}, 1 \mathrm{mM} \mathrm{MgCl}, 1 \mathrm{~mm} \mathrm{CaCl}, 0.1 \mathrm{~mm}$ EDTA, $0.1 \mathrm{~mm}$ DTT, $5 \%$ glycerol, $100 \mu \mathrm{g} / \mathrm{ml}$ bovine senum albumin, $2 \mu \mathrm{g} / \mathrm{ml}$ salmon-sperm DNA, and the glucocorticoid receptor DNAbinding fragment $(125 \mathrm{ng}-1.5 \mu \mathrm{g})$. Binding was allowed to take place for $15 \mathrm{~min}$ at room temperature, and then DNase I 150 $\mathrm{ng} / \mathrm{ml}$ ) was added for $3.5 \mathrm{~min}$ at room temperature. EDTA was added to $10 \mathrm{mM}$, then samples were phenol-chloroform extracted, ethanol-precipitated, and electrophoresed on $6 \%$ polyacrylamide $-50 \%$ urea sequencing gels.

Exonuclease III assays were performed according to $\mathrm{Wu}$ (1985). Binding reactions for exonuclease III assays included 20 fmoles DNA (labeled with $\left[\gamma^{-32} \mathrm{P}\right] \mathrm{ATP}$ and T4 polynucleotide kinase) in $50 \mu$ l of $10 \mathrm{~mm}$ Tris- $\mathrm{HCl}$ (pH 7.8), $50 \mathrm{~mm} \mathrm{NaCl}, 1 \mathrm{~mm}$ EDTA, $5 \%$ glycerol, $1 \mathrm{mM}$ DTT, $5 \mu \mathrm{g}$ of poly[d(I-C)], and $10 \mu \mathrm{g}$ of whole-cell extract from serum-stimulated BALB/c $3 \mathrm{~T} 3$ cells (see above); poly[d(I-C)] and the DNA probe were mixed before addition of the cell extract. After $20 \mathrm{~min}$ at room temperature, $\mathrm{MgCl}_{2}$ was added to $5 \mathrm{mM}$ along with $30-100$ units of exonuclease III, and the incubation was continued for $20 \mathrm{~min}$ at $32^{\circ} \mathrm{C}$. Reactions were terminated by addition of $50 \mu \mathrm{l}$ of $20 \mathrm{~mm}$ EDTA, $1 \%$ sodium dodecylsulfate, $40 \mu \mathrm{g} / \mathrm{ml}$ yeast tRNA, extracted with phenol-chloroform, precipitated with ethanol, and electrophoresed on $8 \%$ polyacrylamide, $50 \%$ urea sequencing gels.

\section{Acknowledgments}

We thank Don Cleveland, Bruce Howard, John Majors, Rick Morimoto, and Keith Yamamoto for plasmids; Len Freedman 
and Keith Yamamoto for the purified glucocorticoid receptor fragment; Barbara Wu for many helpful discussions; and Lester Lau and Barbara Wu for comments on the manuscript. This work was supported by a grant from the National Institutes of Health and by the Searle Scholars Program.

\section{References}

Adler, S., M.L. Waterman, X. He, and M.G. Rosenfeld. 1988. Steroid receptor-mediated inhibition of rat prolactin gene expression does not require the receptor DNA-binding domain. Cell 52: 685-695.

Akerblom, I.E., E.P. Slater, M. Beato, J.D. Baxter, and P.L. Mellon. 1988. Negative regulation by glucocorticoids through interference with a cAMP responsive enhancer. Science 241: 350-353.

Angel, P., M. Imagawa, R. Chiu, B. Stein, R.J. Imbra, H.J. Rahmsdorf, C. Jonat, P. Herrlich, and M. Karin. 1987. Phorbol ester-inducible genes contain a common cis element recognized by a TPA-modulated trans-acting factor. Cell 49: 729-739.

Angel, P., E.A. Allegretto, S.T. Okino, K. Hattori, W.J. Boyle, T. Hunter, and M. Karin. 1988. Oncogene jun encodes a sequence-specific trans-activator similar to AP-1. Nature 332: $166-171$.

Bohmann, D., T.J. Bos, A. Admon, T. Nishimura, P.K. Vogt, and R. Tjian. 1987. Human proto-oncogene c-jun encodes a DNA binding protein with structural and functional properties of transcription factor AP-1. Science 238: 1386-1392.

Bradford, M.M. 1976. A rapid and sensitive method for the quantitation of microgram quantities of protein utilizing the principle of protein-dye binding. Anal. Biochem. 72: 248254.

Camper, S.A., Y.A.S. Yao, and F.M. Rottman. 1985. Hormonal regulation of the bovine prolactin promoter in rat pituitary cells. J. Biol. Chem. 260: 12246-12251.

Chandler, V.L., B.A. Maler, and K.R. Yamamoto. 1983. DNA sequences bound specifically by glucocorticoid receptor in vitro render a heterologous promoter hormone responsive in vivo. Cell 33: 489-499.

Charron, J. and J. Drouin. 1986. Glucocorticoid inhibition of transcription from episomal proopiomelanocortin gene promoter. Proc. Natl. Acad. Sci. 83: 8903-8907.

Chavrier, P., M. Zerial, P. Lemaire, J. Almendral, R. Bravo, and P. Charnay. 1988. A gene encoding a protein with zinc fingers is activated during the G0/Gl transition in cultured cells. EMBO I. 7: 29-35.

Chirgwin, J.M., A.E. Przybyla, R.J. MacDonald, and W.J. Rutter. 1979. Isolation of biologically active ribonucleic acid from sources enriched in ribonuclease. Biochemistry 18: 52945299.

Chiu, R., W.J. Boyle, J. Meek, T. Smeal, T. Hunter, and M. Karin. 1988. The c-fos protein interacts with c-jun/AP-1 to stimulate transcription of $\mathrm{AP}-1$ responsive genes. Cell 54: $541-552$.

Christy, B.A., L.F. Lau, and D. Nathans. 1988. A gene activated in mouse 3T3 cells by serum growth factors encodes a protein with zinc finger sequences. Proc. Natl. Acad. Sci. 85: 7857-7861.

Cohen, D.R. and T. Curran. 1988. fra-1: A serum-inducible, cellular immediate early gene that encodes a FOS-related antigen. Mol. Cell. Biol. 8: 2063-2069.

Davidson, I., J.H. Xiao, R. Rosales, A. Staub, and P. Chambon. 1988. The HeLa cell protein TEF-1 binds specifically and cooperatively to two SV40 enhancer motifs of unrelated sequence. Cell 54: 931-942.
DeFranco, D. and K.R. Yamamoto. 1986. Two different factors act separately or together to specify functionally distinct activities at a single transcriptional enhancer. Mol. Cell. Biol. 6: $993-1001$.

Dupouy, J.P., H. Coffigny, and S. Magre. 1975. Maternal and foetal cortiosterone levels during late pregnancy in rats. $I$. Endocrinol. 65: 347-352.

Fienup, V.K., M.-H. Jeng, R.T. Hamilton, and M. Nilsen-Hamilton. 1986. Relation between the regulation of DNA synthesis and the production of two secreted glycoproteins by 12-O-tetradecanoylphorbol-13-acetate in 3T3 cells and in phorbol ester nonresponsive 3T3 variants. I. Cell. Phys. 129: $151-158$.

Freedman, L.P., B.F. Luisi, Z.R. Korszun, R. Basavappa, P.B. Sigler, and K.R. Yamamoto. 1988. The function and structure of the metal coordinated sites within the glucocorticoid receptor DNA binding domain. Nature 334: 543-546.

Frisch, S.M. and H.E. Ruley. 1987. Transcription from the stromelysin promoter is induced by interleukin-1 and repressed by dexamethasone. J. Biol. Chem. 262: 16300-16304.

Glisin, V., R. Crkvenjakov, and C. Byus. 1974. Ribonucleic acid isolated by cesium chloride centrifugation. Biochemistry 13: $2633-2637$.

Gorman, C.M., L.F. Moffat, and B.H. Howard. 1982a. Recombinant genomes which express chloramphenicol acetyltransferase in mammalian cells. Mol. Cell. Biol. 2: 1044-1051.

Gorman, C., G.T. Merlino, M.C. Willingham, I. Pastan, and B.H. Howard. 1982b. The Rous sarcoma virus long terminal repeat is a strong promoter when introduced into a variety of eukaryotic cells by DNA-mediated transfection. Proc. Natl. Acad. Sci. 79: 6777-6781.

Gorman, C., R. Padmanabhan, and B.H. Howard. 1983. High efficiency DNA-mediated transformation of primate cells. Science 221: 551-553.

Greenberg, M.E. and E.B. Ziff. 1984. Stimulation of 3T3 cells induces transcription of the c-fos proto-oncogene. Nature 311: 433-438.

Guertin, M., H. Larue, D. Bernier, O. Wrange, M. Chevrette, M.-C. Gingras, and L. Belanger. 1988. Enhancer and promoter elements directing activation and glucocorticoid repression of the $\alpha_{1}$-fetoprotein gene in hepatocytes. Mol. Cell. Biol. 8: 1398-1407.

Halazonetis, T.D., K. Georgopoulos, M.E. Greenberg, and P. Leder. 1988. c-jun dimerizes with itself and with c-fos, forming complexes of different binding affinities. Cell 55: 917-924.

Hazel, T.G., D. Nathans, and L.F. Lau. 1988. A gene inducible by serum growth factors encodes a member of the steroid and thyroid hormone receptor superfamily. Proc. Natl. Acad. Sci. 85: 8444-8448.

Herr, W. and J. Clarke. 1986. The SV40 enhancer is composed of multiple functional elements that can compensate for one another. Cell 45: 461-470.

Israel, A. and S.N. Cohen. 1985. Hormonally mediated negative regulation of human pro-opiomelanocortin gene expression after transfection into mouse L cells. Mol. Cell. Biol. 5: 2443-2453.

Jackson, L.L., P. Colosi, F. Talamantes, and D.I.H. Linzer. 1986. Molecular cloning of mouse placental lactogen cDNA. Proc. Natl. Acad. Sci. 83: 8496-8500.

Joseph, L.J., M.M. Le Beau, G.A. Jamieson, Jr., S. Acharya, T.B. Shows, J.D. Rowley, and V.P. Sukhatme. 1988. Molecular cloning, sequencing, and mapping of EGR2, a human early growth response gene encoding a protein with 'zinc-binding finger' structure. Proc. Natl. Acad. Sci. 85: 7164-7168.

Lamph, W.W., P. Wamsley, P. Sassone-Corsi, and I.M. Verma. 
1988. Induction of proto-oncogene JUN/AP-1 by serum and TPA. Nature 334: 629-631.

Lee, S.-J. and D. Nathans. 1987. Secretion of proliferin. Endocrinology 120: 208-213.

Lee, W., P. Mitchell, and R. Tjian. 1987. Purified transcription factor AP-1 interacts with TPA-inducible enhancer elements. Cell 49: 741-752.

Lee, S.-I., F. Talamantes, E. Wilder, D.I.H. Linzer, and D. Nathans. 1988. Trophoblastic giant cells of the mouse placenta as the site of proliferin synthesis. Endocrinology 122: $1761-1768$

Lemaire, P., O. Revelant, R. Bravo, and P. Charnay. 1988. Two mouse genes encoding potential transcription factors with identical DNA binding domains are activated by growth factors in cultured cells. Proc. Natl. Acad. Sci. 85: 46914695.

Linzer, D.I.H. and D. Nathans. 1984a. Nucleotide sequence of a growth-related mRNA encoding a member of the prolactingrowth hormone family. Proc. Natl. Acad. Sci. 81: 42554259 .

- 1984b. Changes in specific mRNAs following serum stimulation of cultured mouse cells: Increase in a prolactinrelated mRNA. Cancer Cells 1: 111-115.

Linzer, D.I.H., S.-J. Lee, L. Ogren, F. Talamantes, and D. Nathans. 1985. Identification of proliferin mRNA and protein in mouse placenta. Proc. Natl. Acad. Sci. 82: 43564359.

Linzer, D.I.H. and J.C. Mordacq. 1987. Transcriptional regulation of proliferin gene expression in response to serum in transfected mouse cells. EMBO I. 6: 2281-2288.

Linzer, D.I.H. and E.L. Wilder. 1987. Control of proliferin gene expression in serum-stimulated mouse cells. Mol. Cell. Biol. 7: 2080-2086.

Lopata, M.A., D.W. Cleveland, and B. Sollner-Webb. 1984. High level transient expression of a chloramphenicol acetyl transferase gene by DEAE-dextran mediated DNA transfection coupled with a dimethyl sulfoxide or glycerol shock treatment. Nucleic Acids Res. 12: 5707-5717.

Majors. J. and H.E. Varmus. 1983. A small region of the mouse mammary tumor virus long terminal repeat confers glucocorticoid hormone regulation of a linked heterologous gene. Proc. Natl. Acad. Sci. 80: 5866-5870.

McKnight, S.L. and R. Kingsbury. 1982. Transcriptional control signals of a eukaryotic protein-coding gene. Science 217: 316-324.

Miesfeld, R., S. Rusconi, P.J. Godowski, B.A. Maler, S. Okret, A.-C. Wikstrom, J.-A. Gustafsson, and K.R. Yamamoto. 1986. Genetic complementation of a glucocorticoid receptor deficiency by expression of cloned receptor cDNA. Cell 46: $389-399$.

Milbrandt, J. 1987. A nerve growth factor-induced gene encodes a possible transcriptional regulatory factor. Science 238: 797-799.

- 1988. Nerve growth factor induces a gene homologuous to the glucocorticoid receptor gene. Neuron 1: 183-188.

Nakabeppu, Y., K. Ryder, and D. Nathans. 1988. DNA binding activities of three murine jun proteins: Stimulation by fos. Cell 55: 907-915.

Nilsen-Hamilton, M., J.M. Shapiro, S.L. Massoglia, and R.T. Hamilton. 1980. Selective stimulation by mitogens of incorporation of ${ }^{35} \mathrm{~S}$-methionine into a family of proteins released into the medium by 3T3 cells. Cell 20: $19-28$.

Ogren, L. and F. Talamantes. 1988. Prolactins of pregnancy and their cellular source. Int. Rev. Cytol. 112: 1-65.

Oro, A.E., S.M. Hollenberg, and R.M. Evans. 1988. Transcriptional inhibition by a glucocorticoid receptor- $\beta$-galactosidase fusion protein. Cell 55: 1109-1114.
Parfett, C.L.J., R.T. Hamilton, B.W. Howell, D.R. Edwards, M. Nilsen-Hamilton, and D.T. Denhardt. 1985. Characterization of a cDNA clone encoding murine mitogen-regulated protein: Regulation of mRNA levels in mortal and immortal cell lines. Mol. Cell. Biol. 5: 3289-3292.

Piette, J., S.-I. Hirai, and M. Yaniv. 1988. Constitutive synthesis of activator protein 1 transcription factor after viral transformation of mouse fibroblasts. Proc. Natl. Acad. Sci. 85: 3401-3405.

Rauscher III, F.J., D.R. Cohen, T. Curran, T.J. Bos, P.K. Vogt, D. Bohmann, R. Tiian, and B.R. Franza, Jr. 1988. Fos-associated protein p39 is the product of the jun proto-oncogene. Science 240: 1010-1016.

Ryder, K. and D. Nathans. 1988. Induction of proto-oncogene c-jun by serum growth factors. Proc. Natl. Acad. Sci. 85: 8464-8467.

Ryder, K., L.F. Lau, and D. Nathans. 1988. A gene activated by growth factors is related to the oncogene v-jun. Proc. Natl. Acad. Sci. 85: 1487-1491.

Ryseck, R. -P., S.I. Hirai, M. Yaniv, and R. Bravo. 1988. Transcriptional activation of c-jun during the $\mathrm{G}^{0} / \mathrm{G}^{\mathrm{I}}$ transition in mouse fibroblasts. Nature 344: 535-537.

Sakai, D.D., S. Helms, J. Carlstedt-Duke, J.-A. Gustafsson, F.M. Rottman, and K.R. Yamamoto. 1988. Hormone-mediated repression: A negative glucocorticoid response element from the bovine prolactin gene. Genes Dev. 2: 1144-1154.

Sassone-Corsi, P., W.W. Lamph, M. Kamps, and I.M. Verma. 1988. fos-associated cellular p39 is related to nuclear transcription factor AP-1. Cell 54: 533-560.

Shaw, G. and R. Kamen. 1986. A conserved AU sequence from the $3^{\prime}$-untranslated region of GM-CSF mRNA mediates selective mRNA degradation. Cell 46: 659-667.

Sukhatme, W.P., X. Cao, L.C. Chang, C.-H. Tsai-Morris, D. Stamenkovich, P.C.P. Ferreira, D.R. Cohen, S.A. Edwards, T.B. Shows, T. Curran, M.M. Le Beau, and E.D. Adamson. 1988. A zinc finger-encoding gene coregulated with c-fos during growth and differentiation, and after cellular depolarization. Cell 53: 37-43.

Sullivan, K.F. and D.W. Cleveland. 1986. Identification of conserved isotype-defining variable region sequences for four vertebrate $\beta$-tubulin polypeptide classes. Proc. Natl. Acad. Sci. 83: 4327-4331.

Weiner, F.R., M.J. Czaja, D.M. Jefferson, M.-A. Giambrone, R. Tur-Kaspa, L.M. Reid, and M.A. Zern. 1987. The effects of dexamethasone on in vitro collagen gene expression. I. Biol. Chem. 262: 6955-6958.

Wilder, E.L. and D.I.H. Linzer. 1986. Expression of multiple proliferin genes in mouse cells. Mol. Cell. Biol. 6: 32833286 .

-1989. Participation of multiple factors including proliferin in the inhibition of myogenic differentiation. Mol. Cell. Biol. 9: 430-441.

$\mathrm{Wu}, \mathrm{C}$. 1985. An exonuclease protection assay reveals heatshock element and TATA box DNA-binding proteins in crude nuclear extracts. Nature 317: 84-87.

Zenke, M., T. Grundstrom, H. Matthes, M. Wintzerith, C. Schatz, A. Wildeman, and P. Chambon. 1986. Multiple sequence motifs are involved in SV40 enhancer function. EMBO J. 5: 387-397.

Zimarino, V. and C. Wu. 1987. Induction of sequence-specific binding of Drosophila heat shock activator protein without protein synthesis. Nature 327: 727-730.

Zoller, M.J. and M. Smith. 1984. Oligonucleotide-directed mutagenesis: A simple method using two oligonucleotide primers and a single-stranded DNA template. DNA 3: 479488. 


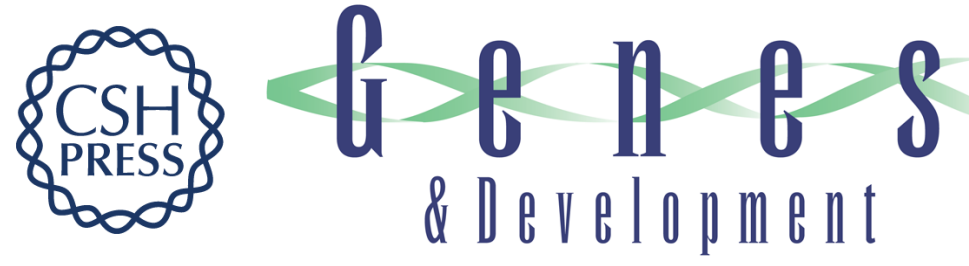

\section{Co-localization of elements required for phorbol ester stimulation and glucocorticoid repression of proliferin gene expression.}

J C Mordacq and D I Linzer

Genes Dev. 1989, 3:

Access the most recent version at doi:10.1101/gad.3.6.760

References This article cites 70 articles, 33 of which can be accessed free at:

http://genesdev.cshlp.org/content/3/6/760.full.html\#ref-list-1

License

Email Alerting

Service

Receive free email alerts when new articles cite this article - sign up in the box at the top right corner of the article or click here.

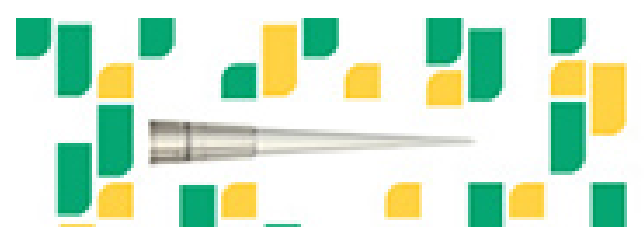

Focused on your science. 